Beimers et al.

\title{
A chemical screen for suppressors of dioxygenase inhibition in a yeast model of familial paraganglioma
}

\author{
William Beimers ${ }^{1}$, Megan Braun ${ }^{1}$, Kaleb Schwinefus, Keenan Pearson, Brandon Wilbanks, and
} L. James Maher, III*

Department of Biochemistry and Molecular Biology

Mayo Clinic College of Medicine and Science

200 First St. SW

Rochester, MN 55905, USA

${ }^{1}$ These authors are co-first authors

*To whom correspondence should be addressed at maher@mayo.edu

Keywords: succinate dehydrogenase, Saccharomyces cerevisiae, paraganglioma, drug screen

Word Count: 5728 
Beimers et al.

\section{Abstract}

2 A fascinating class of familial paraganglioma (PGL) neuroendocrine tumors is driven by loss of

3 the tricarboxylic acid (TCA) cycle enzyme succinate dehydrogenase (SDH) resulting in succinate

4 accumulation as an oncometabolite, and other metabolic derangements. Here we exploit a $S$.

5 cerevisiae yeast model of SDH loss where accumulating succinate, and possibly reactive oxygen

6 species, poison a dioxygenase enzyme required for sulfur scavenging. Using this model we

7 performed a chemical suppression screen for compounds that relieve dioxygenase inhibition. After

8 testing 1280 pharmaceutically-active compounds we identified meclofenoxate HCL, and its

9 hydrolysis product, dimethylaminoethanol (DMAE), as suppressors of dioxygenase intoxication

10 in SDH-loss cells. We show that DMAE acts to alter metabolism so as to normalize the

11 succinate:2-ketoglutarate ratio, improving dioxygenase function. This work raises the possibility

12 that oncometabolite effects might be therapeutically suppressed by drugs that rewire metabolism

13 to reduce the flux of carbon into pathological metabolic pathways.

14

15144 words 
Beimers et al.

\section{INTRODUCTION}

Metabolic dysregulation underlies many diseases. Cancer was characterized by a metabolic

perturbation now known as the Warburg Effect, the observation that cancer cells exhibit glycolytic,

21 rather than oxidative, metabolism even when oxygen is abundant (Warburg, 1956). Since this

22 discovery, many cancers have been found to have other forms of altered metabolism besides the

23 Warburg effect (Kozal et al., 2021; Pavlova and Thompson, 2016). Familial paraganglioma (PGL)

24 is a remarkable example. PGL is a rare neuroendocrine tumor affecting between 1:100,000 and

25 1:300,000 people (Berends et al., 2018; Erickson et al., 2001). The most common form of PGL

26 arises in the chromaffin cells that make up the adrenal medulla, where it is known as

27 pheochromocytoma (Lenders et al., 2005). PGL can be characterized hypertension due to secretion

28 of catecholamines, though most cases are asymptomatic. PGL is typically a slow-growing tumor

29 and many cases are benign and curable by surgery. About $25 \%$ of PGL cases are hereditary, and

30 most hereditary PGLs are linked to pathogenic variants in nuclear genes encoding the four subunits

31 of the tricarboxylic acid (TCA) cycle enzyme succinate dehydrogenase (SDH; also Complex II of

32 the electron transport chain). Such familial SDH-loss PGL cases thus involve mutations in $S D H A$,

$33 S D H B, S D H C, S D H D$ genes, and in $S D H A F 2$, the nuclear gene encoding the factor required for

34 flavin assembly in SDHA. For unknown reasons, variants in SDHB are most penetrant (Astuti et

35 al., 2001; Baysal et al., 2000; Burnichon et al., 2010; Hao et al., 2009; Niemann and Müller, 2000).

36 Mutations are inherited as heterozygous loss-of-function alleles, and tumorigenesis is believed to

37 depend upon sporadic mutational loss or silencing of the remaining gene copy in chromaffin cells.

38 Why tumorigenesis is limited to a particular cell type is also unknown.

It is believed that SDH loss of function drives metabolic reprogramming leading to 
Beimers et al.

41 Current hypotheses focus on the roles of accumulating succinate as an oncometabolite, augmented

42 damage by reactive oxygen species (ROS), and hypersuccinylation (Ishii et al., 2005; Selak et al.,

43 2005; Smestad et al., 2018). ROS production has been shown to increase in SDH-loss model

44 organsims, but it is unclear how much protein and DNA damage results (Adachi et al., 1998; Braun

45 et al., 2019; Ishii et al., 2005; Smith et al., 2007). There is evidence that inherent oxidative stress

46 enhances PGL sensitivity to additional oxidative damage (Liu et al., 2020). Succinate

47 accumulation is perhaps the most promising hypothesis to explain tumorigenesis, with many

48 studies attempting to unravel mechanistic details. SDH loss presumably reprograms central

49 metabolism toward glycolsis because SDH loss breaks the conventional TCA cycle and may alter

50 the flow of high energy electrons into the electron transport chain. Loss of any SDH subunit is

51 believed to disrupt function of the entire SDH complex. This could result in an "obligatory

52 Warburg Effect" with higher dependence on glycolysis, and an accumulation of succinate due to

53 the inability of the nonfunctional SDH to produce fumarate in the TCA cycle (Her and Maher,

54 2015). However, there is also evidence that chromafin cells may generate ATP from residual steps

55 within the TCA cycle and electron transport chain (Kl'učková et al., 2020). Succinate accumulation

56 may extend as well to succinyl-CoA accumulation (one step earlier in the TCA cycle) leading to

57 protein hypersuccinylation (Li et al., 2015; Smestad et al., 2018). The full effects of lysine

58 succinylation on protein function remain incompletely explored. Crucially, accumulated succinate

59 is a competitive inhibitor of an important class of 2-ketoglutarate-dependent dioxygenases. These

60 iron- dependent enzymes oxygenate a substrate by splitting molecular dioxygen. In the process the

61 2-ketoglutarate $(2 \mathrm{KG})$ co-reactant is converted to a succinate byproduct (Loenarz and Schofield,

62 2011). Accumulated succinate can bind in the enzyme active site, inhibiting such dioxygenases,

63 preventing important chemical transformations in cells (Cervera et al., 2009; Koivunen et al., 2007; 
Beimers et al.

64 Letouzé et al., 2013; Peters et al., 2015; Xiao et al., 2012). A greater understanding of the

65 relationship between succinate accumulation and tumorigenesis is the goal of many studies, but a

66 lack of animal models and PGL cell lines continues to challenge progress.

67 In an attempt to envision therapeutics and probe PGL mechanisms, several model systems,

68 including Caenorhabditis elegans, zebrafish, rodents, mammalian cell lines, and the yeast

69 Saccharomyces cerevisiae have been used in lieu of conventional cancer models (Bancos et al.,

70 2013; Braun et al., 2019; Dona et al., 2021; Lussey-Lepoutre et al., 2018; Smestad et al., 2017;

71 Smith et al., 2007). Yeast models of PGL have exploited the conserved mitochondrial role of SDH

72 for studies of metabolic disorders (Bancos et al., 2013; Kregiel, 2012; Lussey-Lepoutre et al.,

73 2018; Smith et al., 2007). S. cerevisiae offers many advantages as a model organism, including its

74 fully-sequenced genome and rich genetics (Feyder et al., 2015; Goffeau et al., 1996). The ease of

75 laboratory maintenance and well-documented techniques for yeast analysis make it well-suited for

76 high-throughput assays as well (Bancos et al., 2013). Haploid SDH subunit deletion strains are

77 readily available, and yeast show profound succinate accumulation upon SDH loss, as do human

78 cells (Feyder et al., 2015; Smestad et al., 2018).

79 Yeast also encode 2-ketoglutarate-dependent dioxygenases, and can therefore serve as a

80 model for succinate accumulation and the subsequent inhibition of these enzymes in this class

81 (Zhang et al., 2020). One dioxygenase in particular, Jlp1p (Fig. 1), is required for sulfur

82 scavenging, converting sulfonates (such as isethionate, ISE) into readily metabolizable sulfites

83 (Hogan et al., 1999). Because Jlp1p is a 2-ketoglutarate-dependent dioxygenase, it can be inhibited

84 by excess succinate. When ISE is the only sulfur source, Jlp1p becomes an essential enzyme for

85 growth. This allows Jlp1p function to be easily monitored simply by assaying cell growth as optical

86 density change over a specified time. In our previous study, we found that a jlp $1 \Delta$ strain is disabled 
Beimers et al.

87 for growth on ISE medium, as expected (Smith et al., 2007). Interestingly, $s d h \Delta$ strains are also

88 partially disabled for growth on ISE, consistent with Jlp1p inhibition by excess succinate. In

89 contrast $j l p 1 \Delta$ and $s d h \Delta$ strains grow equally well on ammonium sulfate (AS), a sulfur source

90 whose utilization does not require Jlp1p activity (Smith et al., 2007).

91 We reasoned that the dependence of yeast on Jlp1p activity in the presence of ISE as sole

92 sulfur source would provide the potential for a chemical suppression screen to identify compounds

93 capable of mitigating Jlp1p inhibition when SDH is lost. Such compounds might act by reducing

94 succinate accumulation or by moderating ROS production that could inhibit Jlp1p through

95 oxidation of the $\mathrm{Fe}^{2+}$ ion required for catalysis (Fig. 1). Based on this concept, we report the results

96 of a screen of the 1280-compound LOPAC library (Sigma \#LO1280), and focus on analysis of one

97 particularly interesting compound, meclofenoxate, and its derivative, dimethylaminoethanol

98 (DMAE) as a lead that suppresses Jlp1p poisoning in SDH-loss yeast strains. To the extent that

99 SDH-loss yeast mimic the stresses of SDH-loss human tumors, meclofenoxate and DMAE

100 exemplify a class of compounds that might suppress tumorigenic dysfunction in SDH-loss cells

101 by rewiring metabolism to reduce the flux of carbon into pathological metabolic pathways.

102

103 MATERIALS AND METHODS

$104 \quad$ Yeast strains

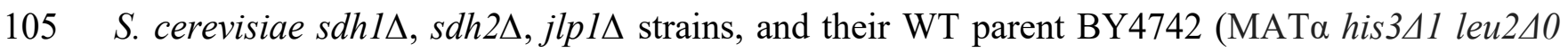

106 lys2 40 ura3 $\Delta 0$ ) were kindly provided by David Katzmann. Strains were maintained on YPGal

107 agar plates (1\% yeast extract, 2\% peptone, 2\% galactose, 2\% agar, all w/v), YPGal liquid media

$108\left(1 \%\right.$ yeast extract, $2 \%$ peptone, $2 \%$ galactose, all w/v) at $25{ }^{\circ} \mathrm{C}$. Most growth experiments were 
Beimers et al.

performed using minimal medium supplemented with $20 \mu \mathrm{M}$ AS or ISE as indicated

110 [Supplemental Table S1;(Cherest and Surdin-Kerjan, 1992)].

\section{Yeast genotyping}

113 Yeast genotyping was performed as described in supplemental methods by growing a cultures (5

$114 \mathrm{~mL})$ to saturation in YPD (1\% yeast extract, $2 \%$ peptone, $2 \%$ dextrose, all w/v) at $30^{\circ} \mathrm{C}$ with

115 shaking at $250 \mathrm{rpm}$.

\section{$117 \quad$ LOPAC screen}

118 The Library of 1280 Pharmacologically Active Compounds (Sigma \#LO1280) was plated by the

119 Institute for Therapeutics Discovery and Development at the University of Minnesota - Twin

120 Cities. $200 \mathrm{~nL}$ of a $10 \mathrm{mM}$ stock of each compound in DMSO were deposited into each well of a

121 96-well polystyrene plate (Corning \#3595). Additional wells received $200 \mathrm{~nL}$ of DMSO to serve

122 as controls. For the screen, $200 \mu \mathrm{L}$ of $s d h 1 \Delta$ yeast culture grown to $0.1 \mathrm{OD}_{600}$ in minimal medium

123 containing $20 \mu \mathrm{M}$ ISE as sulfur source were added to each well (so final compound concentration

124 was $10 \mu \mathrm{M}$ ) and growth was monitored at $600 \mathrm{~nm}$ in a plate reader over the course of $24 \mathrm{~h}$ at $30^{\circ} \mathrm{C}$

125 with constant shaking at $250 \mathrm{rpm}$. The screen was accomplished with sixteen 96-well plates.

126 The power of the chemical screen setup was measured using a conventional $\mathrm{Z}$ score (see

127 below). Growth of WT yeast in ISE media was compared to the growth of $s d h 1 \Delta$ and $s d h 2 \Delta$ strains

128 by $\mathrm{Z}$ score calculation at multiple time points over the course of $24 \mathrm{~h}$. At each point the $\mathrm{Z}$ score

129 was greater than 0, indicating the difference in growth between WT and SDH-loss strains was

130 compatible with a chemical screen. Potential hits were subsequently judged by calculating a Z

131 score according to equation 1: 
Beimers et al.

$$
Z=1-\frac{3 *\left(\sigma_{p}+\sigma_{n}\right)}{\left|\mu_{p}-\mu_{n}\right|}
$$

135 Where $\sigma_{p}$ is the standard deviation of experimental growth wells (the $s d h 1 \Delta$ yeast strain grown in

136 ISE minimal medium in wells with treatment) and $\sigma_{n}$ is the standard deviation of negative control

137 growth wells (the $s d h 1 \Delta$ strain grown in ISE minimal medium in wells with vehicle). $\mu_{p}$ and $\mu_{n}$

138 are the corresponding means of experimental growth wells or negative control growth wells

139 (Zhang et al., 1999). Because each screened compound provided data for a single well vs. 4 data

140 points for the control, the standard deviation of the control was used as a mock parameter for the

141 experimental standard deviation in the calculation. Potential hits were identified from among

142 compounds that stimulated $s d h 1 \Delta$ growth with a Z score greater than zero. Compounds formulated

143 with sulfate ions were excluded from consideration as they provided alternative sources of

144 metabolizable sulfur that bypass the reliance on Jlp1p activity.

146 Yeast growth assay

$147 \mathrm{WT}, s d h 1 \Delta, s d h 2 \Delta$, and jlp $1 \Delta$ strains were grown overnight at $30^{\circ} \mathrm{C}$ in $10 \mathrm{~mL}$ YPGal with shaking 148 at $250 \mathrm{rpm}$. Cultures were then diluted and grown to mid log phase. Equal numbers of cells of each

149 strain were harvested and washed three times with water by centrifugation at $2500 \times g$. Cells from

$150 \mathrm{WT}, s d h 1 \Delta, s d h 2 \Delta$, and $j l p 1 \Delta$ strains were resuspended in minimal media supplemented with 151 either AS or ISE $\left(20 \mu \mathrm{M}\right.$ final concentration) to an $\mathrm{OD}_{600}$ of 0.1 . Yeast culture $(100 \mu \mathrm{L})$ was 152 pipetted into each well along with $100 \mu \mathrm{L}$ of vehicle or drug identified as a hit in the LOPAC 153 screen to a starting $\mathrm{OD}_{600}$ of 0.05 . Each condition was performed with four technical replicates. 154 The growth assay was performed in a 96-well clear plate (Corning \#3595) using a SpectraMax 
Beimers et al.

155 Plus 384 UV/Vis cuvette/microplate reader (Molecular Devices; San Jose, CA). The plate was

156 loaded onto the reader and kept at $30{ }^{\circ} \mathrm{C}$ without shaking with readings taken every 30 min for 24

157 h. Aeration was deemed adequate as the oxygen-dependent Jlp1p-catalyzed processing of ISE to

158 sulfite was supported in WT cells. As described, yeast formed a uniform lawn at the bottom of

159 each well for $\mathrm{OD}_{600}$ readings (Hung et al., 2018). Growth effect of drug was measured by percent

160 growth difference between treated and untreated at the end of the 24-h growth period. Hits were

161 judged on the magnitude of the effect on $s d h 1 \Delta$ and $s d h 2 \Delta$ vs WT and $j l p 1 \Delta$. Error was calculated

162 in R through quadruplicate technical replicates using a one-way ANOVA with a post-hoc Tukey

163 HSD test for significance. Growth curves were generated in R and data analyzed using Microsoft

164 Excel and R.

165

\section{Metabolite analysis}

$167 \mathrm{WT}, s d h 1 \Delta$, and $s d h 2 \Delta$, strains were grown in triplicate for $24 \mathrm{~h}$ in $10 \mathrm{~mL}$ ISE minimal media 168 cultures supplemented with $100 \mu \mathrm{M}$ dimethylaminoethanol (DMAE) (Sigma, 471453-100ML).

169 After $24 \mathrm{~h}$, two $\mathrm{OD}_{600}$ units of each sample were harvested and media was saved for analysis. Cells

170 were washed by centrifugation twice with $\mathrm{PBS}$, then resuspended in $400 \mu \mathrm{L} \mathrm{H}_{2} \mathrm{O}$ containing 30

$171 \mu \mathrm{L}$ concentrated $\mathrm{HClO}_{4}$. This cell suspension was vigorously agitated for $25 \mathrm{sec}$ and subjected to

172 three freeze/thaw cycles on dry ice to promote cell lysis. Cell debris was removed by centrifugation

173 and the lysate collected and neutralized with $170 \mu \mathrm{L} 2 \mathrm{M} \mathrm{KHCO}_{3}$ on ice for analysis as described

174 in supplemental methods.

175

176 Mitochondrial purification and proteomic analysis 
Beimers et al.

177 WT, $s d h 1 \Delta$, and $s d h 2 \Delta$ yeast strains were grown in triplicate to saturation in $1 \mathrm{~L}$ cultures at $30{ }^{\circ} \mathrm{C}$ 178 with shaking at $250 \mathrm{rpm}$. Isolation of mitochondria was performed as described from $8 \mathrm{~g}$ wet

179 weight yeast (Gregg et al., 2009) and proteomic analysis conducted as described in supplemental

180 methods.

182 Western blotting

$183 \mathrm{WT}, s d h 1 \Delta$, and $s d h 2 \Delta$, strains were grown in $10 \mathrm{~mL}$ cultures in minimal media supplemented 184 with $20 \mu \mathrm{M}$ ISE for $24 \mathrm{~h}$ at $30{ }^{\circ} \mathrm{C}$ with shaking at $250 \mathrm{rpm}$. Samples were pelleted by centrifugation 185 at $2500 \times g$ and washed in DTT buffer $(100 \mathrm{mM}$ Tris $\mathrm{pH} 9.4,10 \mathrm{mM}$ DTT), then resuspended in $186100 \mu \mathrm{L}$ zymolyase buffer [1 M sorbitol, $20 \mathrm{mM}$ Tris $\mathrm{pH}$ 7.5, $50 \mathrm{mM}$ EDTA, 1\% $\beta$-mercaptoethanol 187 (v/v), 1-2 mg/mL Zymolyase (AMSBIO, 120493-1)] for lysis at 30 $\mathrm{C}$ for $15 \mathrm{~min}$. Resulting 188 spheroplasts were pelleted by centrifugation at $2000 \times g$ and resuspended in chilled lysis buffer $189[2 \%$ Triton X-100 (v/v), 1\% SDS (w/v), $100 \mathrm{mM} \mathrm{NaCl}, 10 \mathrm{mM}$ Tris $\mathrm{pH}$ 8, $1 \mathrm{mM}$ EDTA] and 50 $190 \mu \mathrm{L}$ chilled glass bead were added. Samples were subjected to 3-5 cycles of vortex mixing (1 min 191 per cycle) with storage on ice between rounds. Samples were subjected to centrifugation at 14,000

$192 \times g$ and the supernatant was stored at $-80{ }^{\circ} \mathrm{C}$ or collected for protein quantification using a BCA 193 assay kit according to the manufacturer's instructions (ThermoFisher 23227). Equal volumes of 194 whole-cell protein extract were subjected to electrophoresis through denaturing $10 \%$ bis-Tris 195 polyacrylamide gels and transferred to PVDF membrane. Equal loading was demonstrated by 196 staining in parallel using Coomassie blue (BioRad). After blocking [5\% non-fat dry milk (w/v), 197 Tris-buffered saline, 1\% Tween-20 (v/v)], membranes were probed with rabbit polyclonal anti198 pansuccinyllysine antibody (PTM Biolabs, PTM-401) at a dilution of 1:1000. Membrane was 
Beimers et al.

washed and incubated with IRDye ${ }^{\circledR} 800 \mathrm{CW}$ goat anti-rabbit IgG secondary antibody (Licor, 926-

32211) and imaged using an Amersham Typhoon instrument.

\section{Fluorescence microscopy}

203 For live-cell detection and quantitation of reactive oxygen species, cells were grown in minimal

204 media $(10 \mathrm{~mL})$ at $30^{\circ} \mathrm{C}$ with shaking at $250 \mathrm{rpm}$ for $24 \mathrm{~h}$ to mid-log phase $\left(0.5 \mathrm{OD}_{600}\right)$. Reactive

205 oxygen species were detected by including $\mathrm{H}_{2}$ DCF-DA (ThermoFisher \#D399) at a final

206 concentration of $10 \mu \mathrm{M}$ during the 24-h incubation. DHE (Dihydroethidine) ROS detection was

207 performed according to previously published methods (Liao et al., 2020). Cells were then

208 harvested $1 \mathrm{~mL}$ at a time, subjected to centrifugation at $10,000 \times g$ and washing three times with

$209 \mathrm{H}_{2} \mathrm{O}$. The resulting cell pellet was resuspended in $20 \mu \mathrm{L} \mathrm{H} \mathrm{H}_{2} \mathrm{O}$, and $5 \mu \mathrm{L}$ was pipetted onto a glass

210 microscope slide and spread into a thin layer with a glass cover slip. Images were captured at room

211 temperature using an Olympus IX70-S1F2 fluorescence microscope (Center Valley, PA) equipped

212 with an Olympus UPIanApo 100× numerical aperture 1.35 oil objective with the complementing

213 immersion oil ( $\mathrm{N}=1.516$, Applied Precision, Issaquah, WA), Standard DeltaVision filters FITC

214 and Rhodamine, and Photometrics CoolSNAP HQ CCD monochrome camera (Teledyne

215 photometrics, Tucson, AZ). Image was acquired using Delta Vision softWoRx (version 3.5.1,

216 Applied Precision, Issaquah, WA) and subsequently processed by FiJi (version: 2.1.0/1.53c,

217 National Institutes of Health, Bethesda, MD). Captured images were exported under the standard

218 DeltaVision file format and converted into 16-bit TIFF images by using Bio-Formats Importer

219 available within Fiji. The contrast and brightness of images were subsequently adjusted within Fiji

220 as well. Data represent quantification from a minimum of three independent labeling experiments

221 with each experiment quantified at least 30 cells. Average cellular fluorescence was quantified 
Beimers et al.

using CellProfiler software. Statistical significance was assessed in R by a two-way ANOVA with

a post-hoc Tukey HSD test.

\section{Protein carbonyl colorimetric assay}

226 Protein carbonyl levels in yeast whole cell lysates were assessed using a colorimetric assay

227 (Sigma-Aldrich, MAK094). WT, $s d h 1 \Delta$, and $s d h 2 \Delta$, strains were grown in $10 \mathrm{~mL}$ minimal media

228 cultures supplemented with ISE $(20 \mu \mathrm{M})$ with or without indicated concentrations of

229 dimethylaminoethanol for $24 \mathrm{~h}$ at $30{ }^{\circ} \mathrm{C}$ with shaking at $250 \mathrm{rpm}$. Protein lysates were prepared as

230 described for western blotting. Carbonyl levels were assayed according to manufacturer's

231 instructions. Data analysis was performed in Microsoft Excel. Statistical significance was assessed

232 in R by a two-way ANOVA with a post-hoc Tukey HSD test in R.

234 RESULTS AND DISCUSSION

Yeast strain characterization

As the present study was based on the previous work of Smith et al. (Smith et al., 2007),

237 we began by validating the four experimental yeast strains (WT, $s d h 1 \Delta, s d h 2 \Delta$, and $j l p 1 \Delta$ ) required

238 for interpreting chemical suppression screen results. PCR genotyping confirmed the identity of

239 each strain (supplemental Fig. S1). Growth testing was performed in AS and ISE minimal

240 galactose liquid media to avoid glucose repression while still enabling fermentation and oxidative

241 metabolism (Kayikci and Nielsen, 2015).

242 Example growth curves for the four strains (Fig. 2 AB) reveal the presence of an expected

243 diauxic shift in the WT and $j l p 1 \Delta$ strains in AS medium, indicating sufficient oxygen and an intact

244 TCA cycle and electron transport chain for oxidative growth. In contrast, SDH-loss strains grow 
Beimers et al.

245 only by fermentation. Statistical analysis of growth at $24 \mathrm{~h}$ is shown in Fig. 2C. Similar overall

246 levels of growth in AS media are observed, as expected. In contrast, growth in ISE minimal

247 galactose media reveals large differences in fitness, also as expected (Smith et al., 2007).

248 Compared to growth in AS, WT growth in ISE is most robust, with $s d h 1 \Delta$ and $s d h 2 \Delta$ showing

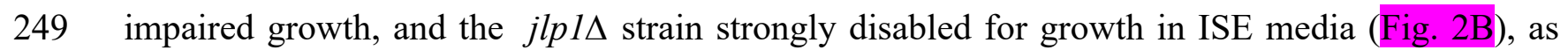

250 previously reported (Smith et al., 2007). These growth differences were statistically significant

251 except that growth of the SDH-loss strains was indistinguishable (Fig. 2D). We interpret the

252 growth defect of SDH-loss yeast strains in ISE medium as evidence that Jlp1p dioxygenase

253 function is compromised in these strains, either due to succinate inhibition or oxidative stress

254 affecting the required ferrous ion. These data confirm the findings of Smith et al. and lay the basis

255 for screening for compounds that suppress the $s d h 1 \Delta$ and $s d h 2 \Delta$ growth defect in ISE media.

257 Proteomic analysis

Previous data indicated that both $s d h 1 \Delta$ and $s d h 2 \Delta$ strains lack SDH activity but that some

259 Sdh1p protein could be detected in $s d h 2 \Delta$ yeast (Smith et al., 2007). In preparation for the chemical

260 suppression screen to identify compounds that rescue Jlp1p activity, we studied potential subtle

261 differences between $s d h 1 \Delta$ and $s d h 2 \Delta$ strains to select one for screening. We therefore performed

262 a detailed proteomic analysis of WT, $s d h 1 \Delta$, and $s d h 2 \Delta$ yeast strains. Mitochondria were isolated

263 from replicate strains grown in YP rich media containing galactose. Extracted proteins were

264 digested with trypsin, peptide lysines acylated using isobaric tags, and the resulting samples 265 analyzed by LC-MS. Approximately 6000 proteins were detected, indicating that even the purified

266 mitochondrial fractions contain a representation of much of the yeast proteome. Quantitative

267 analyses compared detected proteins between $\mathrm{WT} / s d h 1 \Delta, \mathrm{WT} / s d h 2 \Delta$, and $s d h 1 \Delta / s d h 2 \Delta$, reported 
Beimers et al.

as $\log _{2}$ (fold change) with statistical significance as an adjusted P-value (significance $\leq 0.05$ ).

Volcano plots (Fig. 3AB) indicate differences between WT and SDH-loss strains. In the WT/sdh1s abundant in WT and 104 more abundant in $s d h 1 \Delta$. In the WT/sdh2s dataset 1068 proteins were significantly different between WT and $s d h 1 \Delta$ yeast, with 946 more abundant in WT and 122 more abundant in $s d h 1 \Delta$. These results confirm the large remodeling of the yeast proteome driven by SDH loss. We compared the SDH-loss strains in greater detail. Of the 1092 proteins that were differentially expressed upon SDH loss, 991 of these (91\%) were shared between both $s d h 1 \Delta$ and $s d h 2 \Delta, 77(7 \%)$ were unique to the $\mathrm{WT} / s d h 1 \Delta$ dataset, and $24(2 \%)$ were unique to the WT/ $s d h 2 \Delta$ dataset (Fig. 3C). This analysis confirms that $s d h 1 \Delta$ and $s d h 2 \Delta$ are proteomically comparable, and this is affirmed by a correlation plot (Fig. 3D). in SDH-loss cells focused on enzymes of the TCA cycle. Quantitation of these enzyme changes is shown in (Fig. 3E). In this case, ratios are rough estimates due to peptide counting methods, such 283 that complete absence of Sdh1p in $s d h 1 \Delta$ compared to WT yields a nominal $\sim 10$-fold change.

284 Interestingly, loss of Sdh1p reduced most TCA cycle enzymes by 2-3-fold, but reduced SDH 285 subunits (including Shh3p and Shh4p) to a greater extent. and $\operatorname{Sdh} 2 \mathrm{p}$ are lost in $s d h 1 \Delta$ yeast, but a fraction of Sdh1p remains detectable in $s d h 2 \Delta$ yeast (Smith et al., 2007). Such evidence is shown in Fig. S4. This result is reminiscent of reports from 
Beimers et al.

enzyme activity for the residual catalytic subunit, it might contribute in subtle ways to the different

292 phenotypes of tumors driven by loss of different SDH subunits (Guzy et al., 2008). Thus, the small

293 proteomic differences between $s d h 1 \Delta$ and $s d h 2 \Delta$ yeast may serve as a paradigm for small but

294 important differences in comparable mammalian mutants affecting different SDH subunits. For

295 example, the yeast $\mathrm{Sdh} 3 \mathrm{p}$ subunit also functions as a component of the TIM22 mitochondrial

296 translocase system, and yeast also expresses Shh3p and Shh4p paralogs of Sdh3p and Sdh4p, but

297 with unknown functions (Gebert et al., 2011). The overall strong phenotypic and proteomic

298 similarity of $s d h 1 \Delta$ and $s d h 2 \Delta$ strains led us to select the $s d h 1 \Delta$ strain as representative and

299 appropriate for chemical suppression screening.

\section{LOPAC suppression screen}

High-throughput screening (HTS) is an essential approach in drug discovery research

303 (Macarron et al., 2011). We previously conducted a lethality screen of more than 200,000

304 compounds seeking agents selectively toxic to SDH-loss yeast cells as models of SDH-loss human

305 familial PGL (Bancos et al., 2013). The current suppression screen focuses on the concept that the

306 fundamental pathologies of SDH-loss cells are driven by the accumulation of succinate as an

307 oncometabolite inhibiting 2-ketoglutarate-dependent dioxygenases (Cervera et al., 2009;

308 Koivunen et al., 2007; Letouzé et al., 2013; Xiao et al., 2012). We hypothesized that ameliorating

309 succinate toxicity may normalize cell function. Beyond succinate intoxication, it has been

310 proposed that ROS also accumulate in SDH-loss cells, potentially compromising dioxygenase

311 function by oxidation of the ferrous ion critical to dioxygenase function (Liu et al., 2020). The

312 present suppression screen therefore was developed to identify compounds that selectively rescue

313 growth of $s d h 1 \Delta$ yeast by restoring Jlp1p function using growth in ISE as the selection. 
Beimers et al.

The LOPAC 1280 library (Sigma-Aldrich) was screened at $10 \mu \mathrm{M}$ in sixteen 96-well plates with 80 compounds per plate, allowing for growth controls (WT and $s d h 1 \Delta$ strains in AS and ISE

316 media). Each experimental well was seeded with $s d h 1 \Delta$ yeast in ISE media and $\mathrm{OD}_{600}$ readings

317 were taken at 7 timepoints over a 24 -h period and a score modeled on the conventional Z statistic

318 was calculated for each treatment and time (materials and methods). Compounds characterized by

$319 Z>0$ for at least 6 of 7 timepoints were classified as hits (30 of 1280 compounds; Fig. 4A).

$321 \quad$ Hit validation

Because the suppression screen was based on sulfur scavenging, drugs formulated with

323 sulfate or related compounds (16/30 hits) were either excluded or more rigorously tested (Fig. 4B).

324 Four of the initial 30 hits formed colored solutions that interfered with $\mathrm{OD}_{600}$ readings so were

325 excluded. The seven compounds with highest z-scores and no confounding concerns

326 (phenanthroline, phentolamine, reserpine, protoporphyrin IX, minocycline,

327 pyrrolidinedithiocarbamate, and meclofenoxate) were repurchased and subjected to further

328 validation (Supplemental Fig. S7). Validation assays were performed in 96-well plates grown

329 without shaking. Oxygenation was judged adequate by the observation that the oxygen-dependent

330 Jlp1p doxygenase in WT cells allowed strong growth in minimal ISE galactose media. Validation

331 screening compared concentration-dependent effects of test compounds on the growth of WT,

$332 s d h 1 \Delta, s d h 2 \Delta$ and $j l p 1 \Delta$ strains on both ISE and AS media, seeking compounds that selectively

333 improved growth only of $s d h 1 \Delta$ and $s d h 2 \Delta$ strains and only on ISE media.

335 Medicine, 2003) as the most robust and reproducible hit (Fig. 5A). Meclofenoxate is an ester 336 reported to rapidly hydrolyze in water to its substituents, dimethylaminoethanol (DMAE) and 4- 
Beimers et al.

337 chlorophenoxyacetic acid [Supplemental Fig. S2; (Yoshioka et al., 1987)]. Testing of these

338 substituents showed DMAE to be the active agent (Fig. 5B, Supplemental Fig. S8). Meclofenoxate

$339 \mathrm{HCl}$ and DMAE $(25 \mu \mathrm{M})$ were then validated in a full comparative growth assay (Fig. 6),

340 demonstrating their ability to selectively suppress the growth defect of SDH-loss yeast on minimal

341 galactose medium with ISE as sulfur source. Selective partial suppression of the growth defect of

342 SDH-loss yeast in ISE medium, without growth stimulation of WT or $j l p 1 \Delta$ strains in ISE media,

343 or any of the strains in AS media, suggests that meclofenoxate $\mathrm{HCl}$ and DMAE act by improving

344 Jlp1p catalysis of ISE conversion to sulfite. We sought evidence for potential mechanisms of this

345 effect.

\section{Metabolomics}

Meclofenoxate $\mathrm{HCl}$ and DMAE have been studied as anti-aging treatments in animals and

349 in assays of improved brain function (Dowson, 1985; Goldenberg, 1969; Kovalev et al., 2008;

350 Marcer and Hopkins, 1977; Petkov et al., 1990; Zuckerman and Barrett, 1978; Miyazaki et al.,

351 1976), but with little mechanistic detail. There is early published evidence that DMAE activates

352 certain enzymes, including glucose-6-phosphate dehydrogenase (Bielenberg et al., 1986). We used

353 NMR to monitor intracellular levels of succinate and $2 \mathrm{KG}$, the metabolites whose concentration

354 ratio is thought to determine dioxygenase inhibition (Fig. 7 AB). Remarkably, DMAE treatment

355 significantly reduced intracellular succinate concentrations in both $s d h 1 \Delta$ and $s d h 2 \Delta$ yeast strains,

356 but not in WT yeast. DMAE treatment also significantly increased $2 \mathrm{KG}$ levels in $s d h 1 \Delta$ yeast, but

357 not in WT yeast. The resulting reduced succinate:2KG ratios are shown in Fig. $7 \mathrm{C}$, providing

358 evidence that DMAE treatment improves Jlp1p dioxygenase function by partially normalizing the

359 intracellular succinate:2KG ratio in SDH-loss yeast cells. 
Beimers et al.

ROS assays

Though succinate toxicity is thought to be the primary oncometabolite in SDH-loss PGL,

363 evidence shows that reactive oxygen species (ROS) may also accumulate and contribute to

364 development of a cancer phenotype (Ishii et al., 2005; Smith et al., 2007). An altered intracellular

365 redox state has the potential to shift the $\mathrm{Fe}^{2+}: \mathrm{Fe}^{3+}$ balance required for cycles of dioxygenase

366 activity (Guzy et al., 2008; Liu et al., 2020). SDH-loss yeast have been shown to suffer increased

367 ROS production with some increase in formation of protein carbonyl damage (Weber et al., 2015)

368 but no acute evidence of toxic DNA damage (Smith et al., 2007). Assays monitoring the effects of

369 DMAE treatment on protein oxidative damage yielded mixed results (Fig. 8A). DMAE treatment

370 significantly reduced protein carbonyl levels in $s d h 1 \Delta$ cells but not in $s d h 2 \Delta$ or WT cells.

371 To more directly monitor ROS production, live cells were imaged via fluorescence

372 microscopy after treatment with a fluorescein derivative activated by ROS. Results are shown in

373 Fig. 8B and supplementary Fig. S5. Both $s d h 1 \Delta$ and $s d h 2 \Delta$ show significant decreases in

374 fluorescence after treatment with DMAE while WT showed no effect. Interestingly, untreated

$375 s d h 2 \Delta$ cells demonstrated a lower mean fluorescence intensity than untreated WT cells, different

376 from earlier findings that ROS production was similarly increased in both $s d h 1 \Delta$ and $s d h 2 \Delta$ yeast

377 (Smith et al., 2007). Replicative experiments were performed with dihydroethidine (DHE)

378 staining. DMAE exhibited similarly subtle anti-oxidant activity (supplementary Fig. S6). These

379 results suggest that anti-oxidant effects could also play a role in DMAE suppression of Jlp1p

380 inhibition. Previous studies of such effects for DMAE have been limited to much higher

381 concentrations (Gabriela Malanga et al., 2012). 
Beimers et al.

\section{Preliminary DMAE testing in mammalian cells}

The striking ability of meclofenoxate and DMAE to rescue a dioxygenase enzyme in SDH-

loss yeast raises the obvious question of application in mammalian cells. Preliminary studies of

up to millimolar concentrations of DMAE in WT and SDH-loss mammalian cells did not show

normalizing effects on the intracellular succinate: $2 \mathrm{KG}$ ratio (data not shown). Thus, while DMAE

clearly supports the novel concept of suppressing succinate intoxication by altering metabolism in yeast, different compounds will be required for this purpose in mammalian cells.

\section{Implications}

The disease consequences of metabolic perturbation are of central importance in medicine.

Metabolic changes in cancer have been detected and discussed since the discovery of the Warburg

SDH-loss familial PGL presents a unique metabolic state with its fragmented TCA cycle. The

highly conserved nature of SDH across evolution makes our detailed proteomic comparison of $s d h 1 \Delta$ and $s d h 2 \Delta$ strains particularly interesting and relevant for understanding the long-standing paradox that, contrary to expectation for a multi-subunit enzyme, SDH-loss tumors show phenotypes dependent on the affected SDH subunit (Andrews et al., 2018; Guzy et al., 2008; Neumann et al., 2004; Rijken et al., 2019). While loss of any SDH subunit might be predicted to

401 be equally disturbing to cell metabolism, there is evidence from human familial PGL that this is 402 not true. By analogy with the mammalian case where residual SDH complexes may differ upon 403 loss of certain subunits (Bezawork-Geleta et al., 2018), it is intriguing that SDH-loss yeast lacking 404 Sdh1p show subtle proteomic differences from strains lacking Sdh2p. Rather than stressing the 405 similarities between $s d h 1 \Delta$ and $s d h 2 \Delta$ for the purposes of our yeast screen, the subtle differences 
Beimers et al.

between the two strains may illuminate the differential penetrance of PGL caused by SDHA loss

vs. SDHB loss in humans. There are $\sim 20$ differentially-expressed proteins between $s d h 1 \Delta$ and

for cytochrome c oxidase. These proteins are less abundant in the $s d h 2 \Delta$ strain than $s d h 1 \Delta$ strain, giving us a clue as to subtle proteomic differences that might have larger differences on disease

411 progression among different human SDH-loss PGLs. upon SDH loss: succinate accumulation driving dioxygenase inhibition (Koivunen et al., 2007;

414 Selak et al., 2005; Smith et al., 2007; Xiao et al., 2012), ROS overproduction with corresponding 415 damage and redox imbalance (Her and Maher, 2015; Ishii et al., 2005; Kregiel, 2012; Liu et al., 416 2020; Saffi et al., 2006), and succinylation of proteins leading to dysfunction (Smestad et al., 2018, 417 2017). Using the linkage between SDH loss and dioxygenase inhibition as a paradigm, the present 418 chemical suppression screen exploited our ability to connect the inhibition of sulfur scavenging 419 dioxygenase Jlp1p to a nutritional growth assay in a sulfur source requiring Jlp1p function in $S$. 420 cerevisiae (Hogan et al., 1999; Smith et al., 2007). The leading hit from this screen, meclofenoxate $421 \mathrm{HCl}$, and its active derivative DMAE, selectively increase growth of SDH-loss yeast strains by 10$422 \quad 20 \%$ in ISE media.

Though studied superficially over many years, potential mechanisms of meclofenoxate and

424 DMAE effects on metabolism, physiology and lifespan remain poorly understood. Initial studies 425 in the 1970s suggested that these drugs substantially enhance the lifespan of mice (Hochschild, 426 1973; Miyazaki et al., 1976). DMAE was found to affect brain tissue, reducing levels of lipofuscin, 427 an oxidative plaque associated with aging. Lohr and Acara noted that DMAE is similar in structure 428 to choline and could potentially serve as a precursor, and that it could also inhibit choline oxidase 
Beimers et al.

429 (Lohr and Acara, 1990), reducing levels of betaine. Anti-aging effects of DMAE have been studied 430 with an eye to a potential free-radical scavenging mechanism (Gabriela Malanga et al., 2012). Perhaps the most tantalizing published mechanistic observation for DMAE is its reported

432 ability to increase the activity of glucose-6-phosphate dehydrogenase, the rate-limiting initial 433 enzyme of the Pentose Phosphate Pathway (PPP) (Roy and Singh, 1983). The PPP runs parallel 434 to glycolysis, but generates reducing equivalents and key carbon skeletons for nucleotide 435 biosynthesis without generating ATP. We hypothesize that agents such as DMAE may enhance 436 dioxygenase function in SDH-loss cells by shunting carbon flux away from glycolysis and the 437 TCA cycle, reducing the production of succinate at the SDH blockade. We provide further 438 evidence that DMAE relieves oxidative stress by reducing ROS, perhaps normalizing the 439 obligatory $\mathrm{Fe}^{2+}-\mathrm{Fe}^{3+}$ equilibrium essential to the dioxygenase catalytic cycle.

440 Thus, this work illustrates a new paradigm for rewiring metabolism through a small 441 molecule cue that reduces oncometabolite accumulation. Searching for effective small molecules 442 of this type that might affect SDH-loss PGL tumor cells offers a potential route to normalizing 443 inhibited dioxygenase function in such cells. Because dioxygenase inhibition by succinate causes 444 both pseudohypoxia and histone and DNA hypermethylation, such metabolic rewiring could have 445 broad therapeutic effects in familial PGL. 
Beimers et al.

\section{Funding}

This work was supported by the Mayo Foundation, the Mayo Clinic Graduate School of Biomedical Sciences, and the Paradifference Foundation.

\section{Author contributions}

Project conception and manuscript preparation: WB, MB, LJM

Experiments: WB, MB, KS, KP, BW

Data analysis: WB, MB, KS, KP, BW

\section{Acknowledgments}

We thank members of the Maher laboratory for assistance and Marina Ramirez-Alvarado for sharing instrumentation. We acknowledge the excellent assistance of members of the Katzmann laboratory at Mayo Clinic, especially Chun Che Tseng. The excellent support of Ivan Vuckovic and Song Zhang in the Mayo Clinic NMR core facility, Akhilesh Pandey, Zachary Ryan, and Benjamin Madden in the Mayo Clinic Proteomics core facility, and Mai Petterson and Ian Lanza in the Mayo Clinic Metabolomics core facility are acknowledged. 
Beimers et al.

\section{References}

Adachi, H., Fujiwara, Y., Ishii, N., 1998. Effects of oxygen on protein carbonyl and aging in Caenorhabditis elegans mutants with long (age-1) and short (mev-1) life spans. J. Gerontol. A. Biol. Sci. Med. Sci. 53, B240-244. https://doi.org/10.1093/gerona/53a.4.b240

Andrews, K.A., Ascher, D.B., Pires, D.E.V., Barnes, D.R., Vialard, L., Casey, R.T., Bradshaw, N., Adlard, J., Aylwin, S., Brennan, P., Brewer, C., Cole, T., Cook, J.A., Davidson, R., Donaldson, A., Fryer, A., Greenhalgh, L., Hodgson, S.V., Irving, R., Lalloo, F., McConachie, M., McConnell, V.P.M., Morrison, P.J., Murday, V., Park, S.-M., Simpson, H.L., Snape, K., Stewart, S., Tomkins, S.E., Wallis, Y., Izatt, L., Goudie, D., Lindsay, R.S., Perry, C.G., Woodward, E.R., Antoniou, A.C., Maher, E.R., 2018. Tumour risks and genotype-phenotype correlations associated with germline variants in succinate dehydrogenase subunit genes SDHB, SDHC and SDHD. J. Med. Genet. 55, 384-394. https://doi.org/10.1136/jmedgenet-2017-105127

Astuti, D., Latif, F., Dallol, A., Dahia, P.L.M., Douglas, F., George, E., Sköldberg, F., Husebye, E.S., Eng, C., Maher, E.R., 2001. Gene Mutations in the Succinate Dehydrogenase Subunit SDHB Cause Susceptibility to Familial Pheochromocytoma and to Familial Paraganglioma. Am. J. Hum. Genet. 69, 49-54. https://doi.org/10.1086/321282

Bancos, I., Bida, J.P., Tian, D., Bundrick, M., John, K., Holte, M.N., Her, Y.F., Evans, D., Saenz, D.T., Poeschla, E.M., Hook, D., Georg, G., Iii, L.J.M., 2013. High-Throughput Screening for Growth Inhibitors Using a Yeast Model of Familial Paraganglioma. PLOS ONE 8, e56827. https://doi.org/10.1371/journal.pone.0056827

Baysal, B.E., Ferrell, R.E., Willett-Brozick, J.E., Lawrence, E.C., Myssiorek, D., Bosch, A., Mey, A. van der, Taschner, P.E.M., Rubinstein, W.S., Myers, E.N., Richard, C.W., Cornelisse, C.J., Devilee, P., Devlin, B., 2000. Mutations in SDHD, a Mitochondrial Complex II Gene, in Hereditary Paraganglioma. Science 287, 848-851. https://doi.org/10.1126/science.287.5454.848

Berends, A.M.A., Buitenwerf, E., de Krijger, R.R., Veeger, N.J.G.M., van der Horst-Schrivers, A.N.A., Links, T.P., Kerstens, M.N., 2018. Incidence of pheochromocytoma and sympathetic paraganglioma in the Netherlands: A nationwide study and systematic review. Eur. J. Intern. Med. 51, 68-73. https://doi.org/10.1016/j.ejim.2018.01.015

Bezawork-Geleta, A., Wen, H., Dong, L., Yan, B., Vider, J., Boukalova, S., Krobova, L., Vanova, K., Zobalova, R., Sobol, M., Hozak, P., Novais, S.M., Caisova, V., Abaffy, P., Naraine, R., Pang, Y., Zaw, T., Zhang, P., Sindelka, R., Kubista, M., Zuryn, S., Molloy, M.P., Berridge, M.V., Pacak, K., Rohlena, J., Park, S., Neuzil, J., 2018. Alternative assembly of respiratory complex II connects energy stress to metabolic checkpoints. Nat. Commun. 9, 2221. https://doi.org/10.1038/s41467-018-04603-z

Bielenberg, G.W., Hayn, C., Krieglstein, J., 1986. Effects of cerebro-protective agents on enzyme activities of rat primary glial cultures and rat cerebral cortex. Biochem. Pharmacol. 35, 2693-2702. https://doi.org/10.1016/0006-2952(86)90177-2

Braun, M.M., Damjanac, T., Zhang, Y., Chen, C., Hu, J., Maher, L.J., 2019. Modeling succinate dehydrogenase loss disorders in $\mathrm{C}$. elegans through effects on hypoxia-inducible factor. PLOS ONE 14, e0227033. https://doi.org/10.1371/journal.pone.0227033

Burnichon, N., Brière, J.-J., Libé, R., Vescovo, L., Rivière, J., Tissier, F., Jouanno, E., Jeunemaitre, X., Bénit, P., Tzagoloff, A., Rustin, P., Bertherat, J., Favier, J., Gimenez- 
Beimers et al.

Roqueplo, A.-P., 2010. SDHA is a tumor suppressor gene causing paraganglioma. Hum. Mol. Genet. 19, 3011-3020. https://doi.org/10.1093/hmg/ddq206

Cervera, A.M., Bayley, J.-P., Devilee, P., McCreath, K.J., 2009. Inhibition of succinate dehydrogenase dysregulates histone modification in mammalian cells. Mol. Cancer 8, 89. https://doi.org/10.1186/1476-4598-8-89

Cherest, H., Surdin-Kerjan, Y., 1992. Genetic analysis of a new mutation conferring cysteine auxotrophy in Saccharomyces cerevisiae: updating of the sulfur metabolism pathway. Genetics 130, 51-58.

de Alteriis, E., Cartenì, F., Parascandola, P., Serpa, J., Mazzoleni, S., 2018. Revisiting the Crabtree/Warburg effect in a dynamic perspective: a fitness advantage against sugarinduced cell death. Cell Cycle 17, 688-701. https://doi.org/10.1080/15384101.2018.1442622

Dona, M., Waaijers, S., Richter, S., Eisenhofer, G., Korving, J., Kamel, S.M., Bakkers, J., Rapizzi, E., Rodenburg, R.J., Zethof, J., Gorissen, M., Flik, G., Deen, P.M.T., Timmers, H.J.L.M., 2021. Loss of sdhb in zebrafish larvae recapitulates human paraganglioma characteristics. Endocr. Relat. Cancer 28, 65-77. https://doi.org/10.1530/ERC-20-0308

Dowson, J.H., 1985. Quantitative studies of the effects of aging, meclofenoxate, and dihydroergotoxine on intraneuronal lipopigment accumulation in the rat. Exp. Gerontol. 20, 333-340. https://doi.org/10.1016/0531-5565(85)90013-0

Erickson, D., Kudva, Y.C., Ebersold, M.J., Thompson, G.B., Grant, C.S., van Heerden, J.A., Young, W.F., Jr., 2001. Benign Paragangliomas: Clinical Presentation and Treatment Outcomes in 236 Patients. J. Clin. Endocrinol. Metab. 86, 5210-5216. https://doi.org/10.1210/jcem.86.11.8034

Feyder, S., De Craene, J.-O., Bär, S., Bertazzi, D.L., Friant, S., 2015. Membrane Trafficking in the Yeast Saccharomyces cerevisiae Model. Int. J. Mol. Sci. 16, 1509-1525. https://doi.org/10.3390/ijms16011509

Gabriela Malanga, Maria Belen Aguiar, Hugo D. Martinez, Susana Puntarulo, 2012. New Insights on Dimethylaminoethanol (DMAE) Features as a Free Radical Scavenger. Drug Metab. Lett. 6, 54-59. https://doi.org/10.2174/187231212800229282

Gebert, N., Gebert, M., Oeljeklaus, S., von der Malsburg, K., Stroud, D.A., Kulawiak, B., Wirth, C., Zahedi, R.P., Dolezal, P., Wiese, S., Simon, O., Schulze-Specking, A., Truscott, K.N., Sickmann, A., Rehling, P., Guiard, B., Hunte, C., Warscheid, B., van der Laan, M., Pfanner, N., Wiedemann, N., 2011. Dual Function of Sdh3 in the Respiratory Chain and TIM22 Protein Translocase of the Mitochondrial Inner Membrane. Mol. Cell 44, 811818. https://doi.org/10.1016/j.molcel.2011.09.025

Goffeau, A., Barrell, B.G., Bussey, H., Davis, R.W., Dujon, B., Feldmann, H., Galibert, F., Hoheisel, J.D., Jacq, C., Johnston, M., Louis, E.J., Mewes, H.W., Murakami, Y., Philippsen, P., Tettelin, H., Oliver, S.G., 1996. Life with 6000 Genes. Science 274, 546567. https://doi.org/10.1126/science.274.5287.546

Goldenberg, M.M., 1969. Effect of atropine and DMAE (a hemicholinium derivative) on contractile responses of the guinea pig ileum. Can. J. Physiol. Pharmacol. 47, 185-192. https://doi.org/10.1139/y69-032

Gregg, C., Kyryakov, P., Titorenko, V.I., 2009. Purification of Mitochondria from Yeast Cells. J. Vis. Exp. JoVE 1417. https://doi.org/10.3791/1417

Guzy, R.D., Sharma, B., Bell, E., Chandel, N.S., Schumacker, P.T., 2008. Loss of the SdhB, but Not the SdhA, Subunit of Complex II Triggers Reactive Oxygen Species-Dependent 
Beimers et al.

Hypoxia-Inducible Factor Activation and Tumorigenesis. Mol. Cell. Biol. 28, 718-731. https://doi.org/10.1128/MCB.01338-07

Hao, H.-X., Khalimonchuk, O., Schraders, M., Dephoure, N., Bayley, J.-P., Kunst, H., Devilee, P., Cremers, C.W.R.J., Schiffman, J.D., Bentz, B.G., Gygi, S.P., Winge, D.R., Kremer, H., Rutter, J., 2009. SDH5, a Gene Required for Flavination of Succinate Dehydrogenase, Is Mutated in Paraganglioma. Science 325, 10.1126/science.1175689.

https://doi.org/10.1126/science.1175689

Her, Y.F., Maher, L.J., 2015. Succinate Dehydrogenase Loss in Familial Paraganglioma:

Biochemistry, Genetics, and Epigenetics. Int. J. Endocrinol. 2015, 1-14.

https://doi.org/10.1155/2015/296167

Hochschild, R., 1973. Effect of dimethylaminoethyl p-chlorophenoxyacetate on the life span of male swiss webster albino mice. Exp. Gerontol. 8, 177-183.

https://doi.org/10.1016/0531-5565(73)90024-7

Hogan, D.A., Auchtung, T.A., Hausinger, R.P., 1999. Cloning and Characterization of a Sulfonate $\alpha-$-Ketoglutarate Dioxygenase from Saccharomyces cerevisiae. J. Bacteriol. 181, 5876-5879. https://doi.org/10.1128/JB.181.18.5876-5879.1999

Hung, C.-W., Martínez-Márquez, J.Y., Javed, F.T., Duncan, M.C., 2018. A simple and inexpensive quantitative technique for determining chemical sensitivity in Saccharomyces cerevisiae. Sci. Rep. 8, 11919. https://doi.org/10.1038/s41598-01830305-z

Ishii, T., Yasuda, K., Akatsuka, A., Hino, O., Hartman, P.S., Ishii, N., 2005. A Mutation in the SDHC Gene of Complex II Increases Oxidative Stress, Resulting in Apoptosis and Tumorigenesis. Cancer Res. 65, 203-209.

Kayikci, Ö., Nielsen, J., 2015. Glucose repression in Saccharomyces cerevisiae. FEMS Yeast Res. 15. https://doi.org/10.1093/femsyr/fov068

Kl'učková, K., Thakker, A., Vettore, L., Escribano-Gonzalez, C., Hindshaw, R.L., Tearle, J.L.E., Goncalves, J., Kaul, B., Lavery, G.G., Favier, J., Tennant, D.A., 2020. Succinate dehydrogenase deficiency in a chromaffin cell model retains metabolic fitness through the maintenance of mitochondrial NADH oxidoreductase function. FASEB J. 34, 303315. https://doi.org/10.1096/fj.201901456R

Koivunen, P., Hirsilä, M., Remes, A.M., Hassinen, I.E., Kivirikko, K.I., Myllyharju, J., 2007. Inhibition of Hypoxia-inducible Factor (HIF) Hydroxylases by Citric Acid Cycle Intermediates: POSSIBLE LINKS BETWEEN CELL METABOLISM AND STABILIZATION OF HIF *. J. Biol. Chem. 282, 4524-4532. https://doi.org/10.1074/jbc.M610415200

Kovalev, G.I., Firstova, I.I., Salimov, R.M., 2008. [Effects of piracetam and meclofenoxate on the brain NMDA and nicotinic receptors in mice with different exploratory efficacy in the cross maze test]. Eksp. Klin. Farmakol. 71, 12-17.

Kozal, K., Jóźwiak, P., Krześlak, A., 2021. Contemporary Perspectives on the Warburg Effect Inhibition in Cancer Therapy. Cancer Control 28, 10732748211041244. https://doi.org/10.1177/10732748211041243

Kregiel, D., 2012. Succinate Dehydrogenase of Saccharomyces cerevisiae - The Unique Enzyme of TCA Cycle - Current Knowledge and New Perspectives, in: Canuto, R.A. (Ed.), Dehydrogenases. InTech. https://doi.org/10.5772/48413

Lenders, J.W., Eisenhofer, G., Mannelli, M., Pacak, K., 2005. Phaeochromocytoma. The Lancet 366, 665-675. https://doi.org/10.1016/S0140-6736(05)67139-5 
Beimers et al.

Letouzé, E., Martinelli, C., Loriot, C., Burnichon, N., Abermil, N., Ottolenghi, C., Janin, M., Menara, M., Nguyen, A.T., Benit, P., Buffet, A., Marcaillou, C., Bertherat, J., Amar, L., Rustin, P., De Reyniès, A., Gimenez-Roqueplo, A.-P., Favier, J., 2013. SDH Mutations Establish a Hypermethylator Phenotype in Paraganglioma. Cancer Cell 23, 739-752. https://doi.org/10.1016/j.ccr.2013.04.018

Li, F., He, Xiadi, Ye, D., Lin, Y., Yu, H., Yao, C., Huang, L., Zhang, J., Wang, F., Xu, S., Wu, X., Liu, L., Yang, C., Shi, J., He, Xiaoyang, Liu, J., Qu, Y., Guo, F., Zhao, J., Xu, W., Zhao, S., 2015. NADP+-IDH Mutations Promote Hypersuccinylation that Impairs Mitochondria Respiration and Induces Apoptosis Resistance. Mol. Cell 60, 661-675. https://doi.org/10.1016/j.molcel.2015.10.017

Liao, P.-C., Yang, E.J., Pon, L.A., 2020. Live-Cell Imaging of Mitochondrial Redox State in Yeast Cells. STAR Protoc. 1, 100160. https://doi.org/10.1016/j.xpro.2020.100160

Liu, Y., Pang, Y., Zhu, B., Uher, O., Caisova, V., Huynh, T.-T., Taieb, D., Vanova, K.H., Ghayee, H.K., Neuzil, J., Levine, M., Yang, C., Pacak, K., 2020. Therapeutic Targeting of SDHB-Mutated Pheochromocytoma/Paraganglioma with Pharmacologic Ascorbic Acid. Clin. Cancer Res. 26, 3868-3880. https://doi.org/10.1158/1078-0432.CCR-19-2335

Loenarz, C., Schofield, C.J., 2011. Physiological and biochemical aspects of hydroxylations and demethylations catalyzed by human 2-oxoglutarate oxygenases. Trends Biochem. Sci. 36, 7-18. https://doi.org/10.1016/j.tibs.2010.07.002

Lohr, J., Acara, M., 1990. Effect of dimethylaminoethanol, an inhibitor of betaine production, on the disposition of choline in the rat kidney. J. Pharmacol. Exp. Ther. 252, 154-158.

Lussey-Lepoutre, C., Buffet, A., Morin, A., Goncalves, J., Favier, J., 2018. Rodent models of pheochromocytoma, parallels in rodent and human tumorigenesis. Cell Tissue Res. 372, 379-392. https://doi.org/10.1007/s00441-018-2797-y

Macarron, R., Banks, M.N., Bojanic, D., Burns, D.J., Cirovic, D.A., Garyantes, T., Green, D.V.S., Hertzberg, R.P., Janzen, W.P., Paslay, J.W., Schopfer, U., Sittampalam, G.S., 2011. Impact of high-throughput screening in biomedical research. Nat. Rev. Drug Discov. 10, 188-195. https://doi.org/10.1038/nrd3368

Marcer, D., Hopkins, S.M., 1977. The Differential Effects of Meclofenoxate on Memory Loss in the Elderly. Age Ageing 6, 123-131. https://doi.org/10.1093/ageing/6.2.123

Miyazaki, H, Nambu, K., Minaki, Y., Hashimoto, M., Nakamura, K., 1976. Comparative Studies on the Metabolism of $\beta$-Dimethylaminoethanol in the Mouse Brain and Liver Following Administration of $\beta$-Dimethyl-aminoethanol and Its $\mathrm{p}$-Chlorophenoxyacetate, Meclofenoxate. Chem. Pharm. Bull. (Tokyo) 24, 763-769. https://doi.org/10.1248/cpb.24.763

Neumann, H.P.H., Pawlu, C., Pęczkowska, M., Bausch, B., McWhinney, S.R., Muresan, M., Buchta, M., Franke, G., Klisch, J., Bley, T.A., Hoegerle, S., Boedeker, C.C., Opocher, G., Schipper, J., Januszewicz, A., Eng, C., for the European-American Paraganglioma Study Group, 2004. Distinct Clinical Features of Paraganglioma Syndromes Associated With SDHB and SDHD Gene Mutations. JAMA 292, 943-951. https://doi.org/10.1001/jama.292.8.943

Niemann, S., Müller, U., 2000. Mutations in SDHC cause autosomal dominant paraganglioma, type 3. Nat. Genet. 26, 268-270. https://doi.org/10.1038/81551

Pavlova, N.N., Thompson, C.B., 2016. The Emerging Hallmarks of Cancer Metabloism. Cell Metab. 23, 27-47. https://doi.org/10.1016/j.cmet.2015.12.006 
Beimers et al.

Peters, J.P., Her, Y.F., Maher, L.J., III, 2015. Modeling dioxygenase enzyme kinetics in familial paraganglioma. Biol. Open 4, 1281-1289. https://doi.org/10.1242/bio.013623

Petkov, V.D., Stancheva, S.L., Tocuschieva, L., Petkov, V.V., 1990. Changes in brain biogenic monoamines induced by the nootropic drugs adafenoxate and meclofenoxate and by citicholine (experiments on rats). Gen. Pharmacol. 21, 71-75. https://doi.org/10.1016/0306-3623(90)90598-g

Rijken, J.A., van Hulsteijn, L.T., Dekkers, O.M., Niemeijer, N.D., Leemans, C.R., Eijkelenkamp, K., van der Horst-Schrivers, A.N.A., Kerstens, M.N., van Berkel, A., Timmers, H.J.L.M., Kunst, H.P.M., Bisschop, P.H.L.T., Dreijerink, K.M.A., van Dooren, M.F., Hes, F.J., Jansen, J.C., Corssmit, E.P.M., Hensen, E.F., 2019. Increased Mortality in SDHB but Not in SDHD Pathogenic Variant Carriers. Cancers 11, 103.

https://doi.org/10.3390/cancers11010103

Roy, D., Singh, R., 1983. Age-related changes in glucose-6-phosphate dehydrogenase and 6phosphogluconate dehydrogenase in the subcellular fractions from the rat brain and the effect of dimethylaminoethanol. Biochem. Int.

Saffi, J., Sonego, L., Varela, Q.D., Salvador, M., 2006. Antioxidant activity of L-ascorbic acid in wild-type and superoxide dismutase deficient strains of Saccharomyces cerevisiae. Redox Rep. 11, 179-184. https://doi.org/10.1179/135100006X116691

Selak, M.A., Armour, S.M., MacKenzie, E.D., Boulahbel, H., Watson, D.G., Mansfield, K.D., Pan, Y., Simon, M.C., Thompson, C.B., Gottlieb, E., 2005. Succinate links TCA cycle dysfunction to oncogenesis by inhibiting HIF- $\alpha$ prolyl hydroxylase. Cancer Cell 7, 7785. https://doi.org/10.1016/j.ccr.2004.11.022

Smestad, J., Erber, L., Chen, Y., Maher, L.J., 2018. Chromatin Succinylation Correlates with Active Gene Expression and Is Perturbed by Defective TCA Cycle Metabolism. iScience 2, 63-75. https://doi.org/10.1016/j.isci.2018.03.012

Smestad, J., Hamidi, O., Wang, L., Holte, M.N., Khazal, F.A., Erber, L., Chen, Y., Maher, L.J., 2017. Characterization and metabolic synthetic lethal testing in a new model of SDH-loss familial pheochromocytoma and paraganglioma. Oncotarget 9, 6109-6127. https://doi.org/10.18632/oncotarget.23639

Smith, E.H., Janknecht, R., Maher, L.J., 2007. Succinate inhibition of $\alpha$-ketoglutarate-dependent enzymes in a yeast model of paraganglioma. Hum. Mol. Genet. 16, 3136-3148. https://doi.org/10.1093/hmg/ddm275

The Science of Anti-aging Medicine, 2003. . American Academy of Anti-Aging Med.

Warburg, O., 1956. On the Origin of Cancer Cells. Science 123, 309-314. https://doi.org/10.1126/science.123.3191.309

Weber, D., Davies, M.J., Grune, T., 2015. Determination of protein carbonyls in plasma, cell extracts, tissue homogenates, isolated proteins: Focus on sample preparation and derivatization conditions. Redox Biol. 5, 367-380. https://doi.org/10.1016/j.redox.2015.06.005

Xiao, M., Yang, H., Xu, W., Ma, S., Lin, H., Zhu, H., Liu, L., Liu, Y., Yang, C., Xu, Y., Zhao, S., Ye, D., Xiong, Y., Guan, K.-L., 2012. Inhibition of $\alpha$-KG-dependent histone and DNA demethylases by fumarate and succinate that are accumulated in mutations of $\mathrm{FH}$ and SDH tumor suppressors. Genes Dev. 26, 1326-1338. https://doi.org/10.1101/gad.191056.112 
Beimers et al.

Yoshioka, S., Aso, Y., Uchiyama, M., 1987. Kinetics of hydrolysis of meclofenoxate hydrochloride in human plasma. J. Pharm. Pharmacol. 39, 215-218.

https://doi.org/10.1111/j.2042-7158.1987.tb06251.x

Zhang, J., van den Herik, B.M., Wahl, S.A., 2020. Alpha-ketoglutarate utilization in Saccharomyces cerevisiae: transport, compartmentation and catabolism. Sci. Rep. 10, 12838. https://doi.org/10.1038/s41598-020-69178-6

Zhang, J.-H., Chung, T.D.Y., Oldenburg, K.R., 1999. A Simple Statistical Parameter for Use in Evaluation and Validation of High Throughput Screening Assays. J. Biomol. Screen. 4, 67-73. https://doi.org/10.1177/108705719900400206

Zuckerman, B.M., Barrett, K.A., 1978. Effects of pca and dmae on the nematode caenorhabditis briggsae. Exp. Aging Res. 4, 133-139. https://doi.org/10.1080/03610737808257136 


\section{Figure legends}

Fig. 1. Dioxygenase inhibition in SDH-mutant yeast. Jlp1p dioxygenase conversion of $2 \mathrm{KG}$ and sulfonate (ISE) into bioavailable sulfite, with succinate and an aldehyde (glycoaldehyde in this case) as byproducts. The reaction uses molecular oxygen and an enzyme-bound $\mathrm{Fe}^{2+}$ ion that undergoes REDOX cycling. In SDH-loss cells, both ROS and succinate accumulate. Depicted are possible mechanisms of Jlp1 inhibition iunder such conditions. Accumulated succinate causes competitive inhibition at the enzyme active site. Increased ROS may interfere with REDOX cycling of $\mathrm{Fe}^{2+}$ in the active site.

Fig. 2. Representative yeast growth phenotypes. A. Growth in ammonium sulfate medium. B. Growth in ISE medium. C. Growth in ammonium sulfate medium at $24 \mathrm{~h}$. D. Growth in ISE medium at $24 \mathrm{~h}$. Statistical significance reflecting four replicates is reported using a one-way ANOVA with a post-hoc Tukey HSD test for significance. P-values: $* \leq 0.05, * * \leq 0.01, * * * \leq$ 0.001 .

Fig. 3. Proteomic comparison of $s d h 1 \Delta$ and $s d h 2 \Delta$ yeast strains. A, B. Volcano plots. Shading denotes significance $\left(p<0.05\right.$ and $\mid \log _{2}$ (fold change) $\mid \geq 1.5$. Protein counts in each category are indicated. C. Venn diagram indicating relationship between proteins significantly different from WT for $s d h 1 \Delta$ and $s d h 2 \Delta$ cells. D. Correlation between $s d h 1 \Delta$ and $s d h 2 \Delta$ proteome alterations. Gray points indicate genes with non-significant fold changes. E. Results of DAVID functional analysis indicating loss of TCA cycle enzyme polypeptides, especially SDH subunits, in $s d h 1 \Delta$ yeast. 
Beimers et al.

Fig. 4. Results of LOPAC chemical suppression screen. A. Effects of LOPAC compounds on $s d h 1 \Delta$ yeast growth in ISE medium, ranked for compounds with Z Scores $\geq-5$. Red box at upper right indicates compounds with $Z \geq 0$. B. Detail of LOPAC compounds inducing $Z$ Scores $>0$, indicating whether the compound formulation itself did (+) or did not (-) contain bioavailable sulfate. Arrow indicates meclofenoxate $\mathrm{HCl}(\mathrm{Z}=0.40)$.

Fig. 5. Dose-response data (percent change relative to untreated) for the indicated yeast strains in ISE medium and the indicated concentrations of (A) meclofenoxate and (B) DMAE, both dissolved in water. Error bars indicate standard deviation reflecting 4 technical replicates propagated to $\%$ growth effect vs. untreated.

Fig. 6. Effect of $25 \mu \mathrm{M}$ treatment of the indicated drugs on yeast growth at $24 \mathrm{~h}$ in (A) AS and (B) ISE media. Drug effects are shown as \% growth change in (C) AS and (D) ISE media for the indicated drug treatments. Statistical significance is reported using two-way ANOVA with a posthoc Tukey HSD test for significance. $p$-values: $* \leq 0.05, * * \leq 0.01, * * * \leq 0.001$. In panel B Error bars indicate standard deviation of 4 technical replicates propagated to \% growth effect vs. untreated.

Fig 7. Effect of $100 \mu \mathrm{M}$ DMAE on (A) intracellular succinate, and (B) intracellular $2 \mathrm{KG}$ concentrations in ISE medium after $24 \mathrm{~h}$. Indicated level of statistical significance from a two-way ANOVA with a post-hoc Tukey HSD test for significance. * indicates $\mathrm{P} \leq 0.05$ based on 3 replicates. C. Ratio of succinate concentration to $2 \mathrm{KG}$ concentration in samples. Error bars represent standard deviation for 3 replicates. 
bioRxiv preprint doi: https://doi.org/10.1101/2021.11.08.467804; this version posted November 8,2021 . The copyright holder for this preprint (which was not certified by peer review) is the author/funder, who has granted bioRxiv a license to display the preprint in perpetuity. It is made available under aCC-BY-NC-ND 4.0 International license.

Beimers et al.

Fig. 8. Effect of $100 \mu \mathrm{M}$ DMAE treatment on measures of oxidative stress in ISE medium after 24

h. A. Assay of protein carbonyl products. B. Assay of ROS in live cells. Indicated level of statistical significance from a two-way ANOVA with a post-hoc Tukey HSD test for significance. * indicates $\mathrm{P} \leq 0.05$ and ** indicates $\mathrm{P} \leq 0.01$ based on 12 replicates $(\mathrm{A})$ and $30-60$ cells $(\mathrm{B})$. 


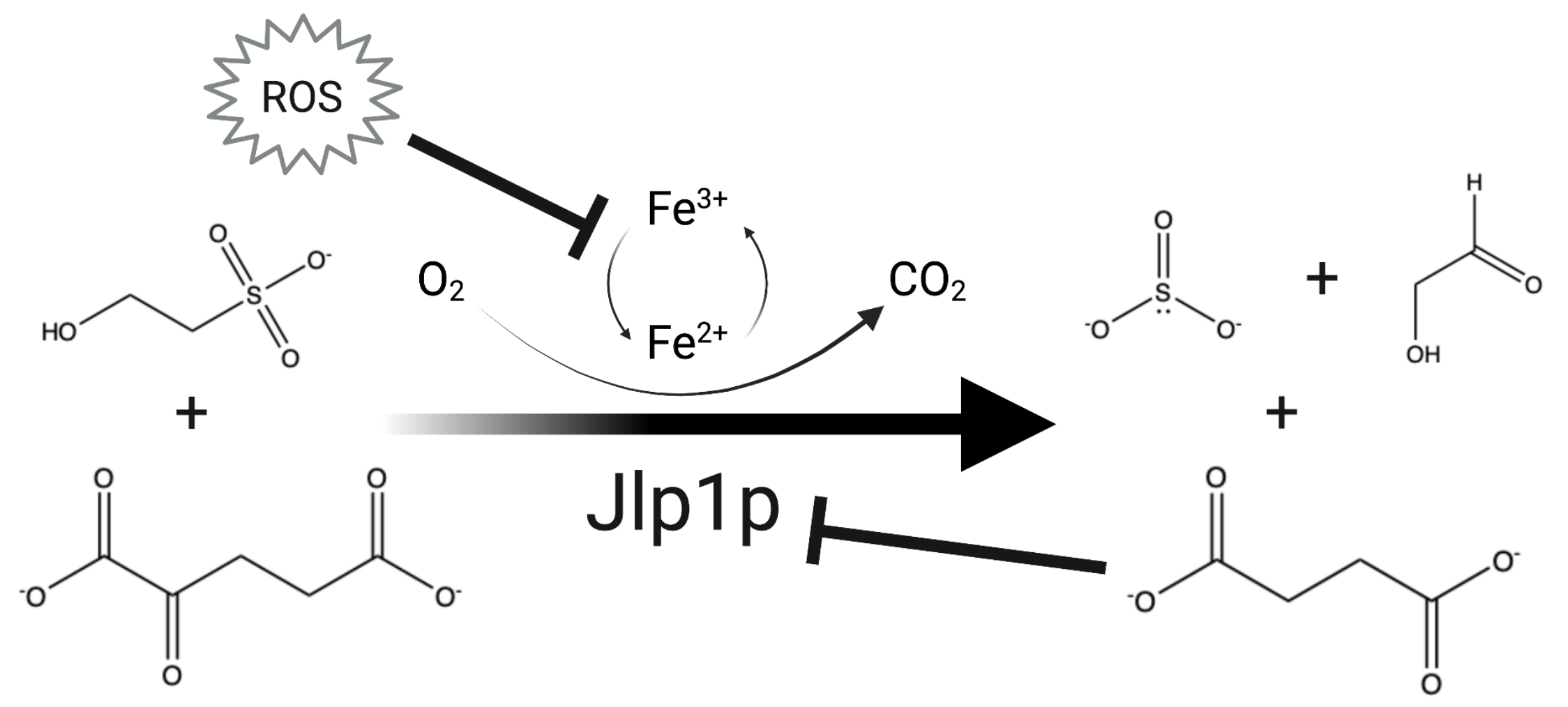

Fig 1 

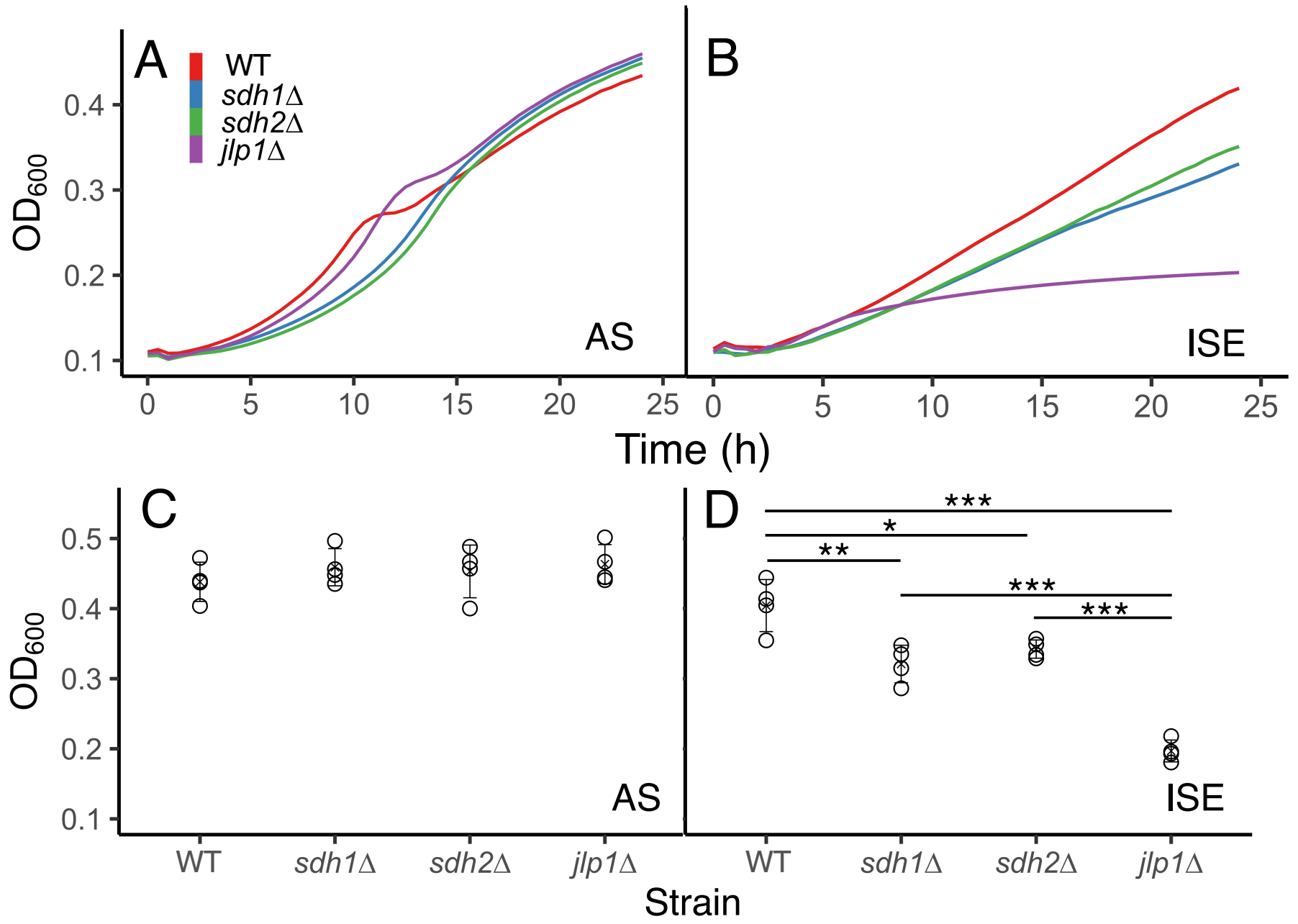

Fig 2 

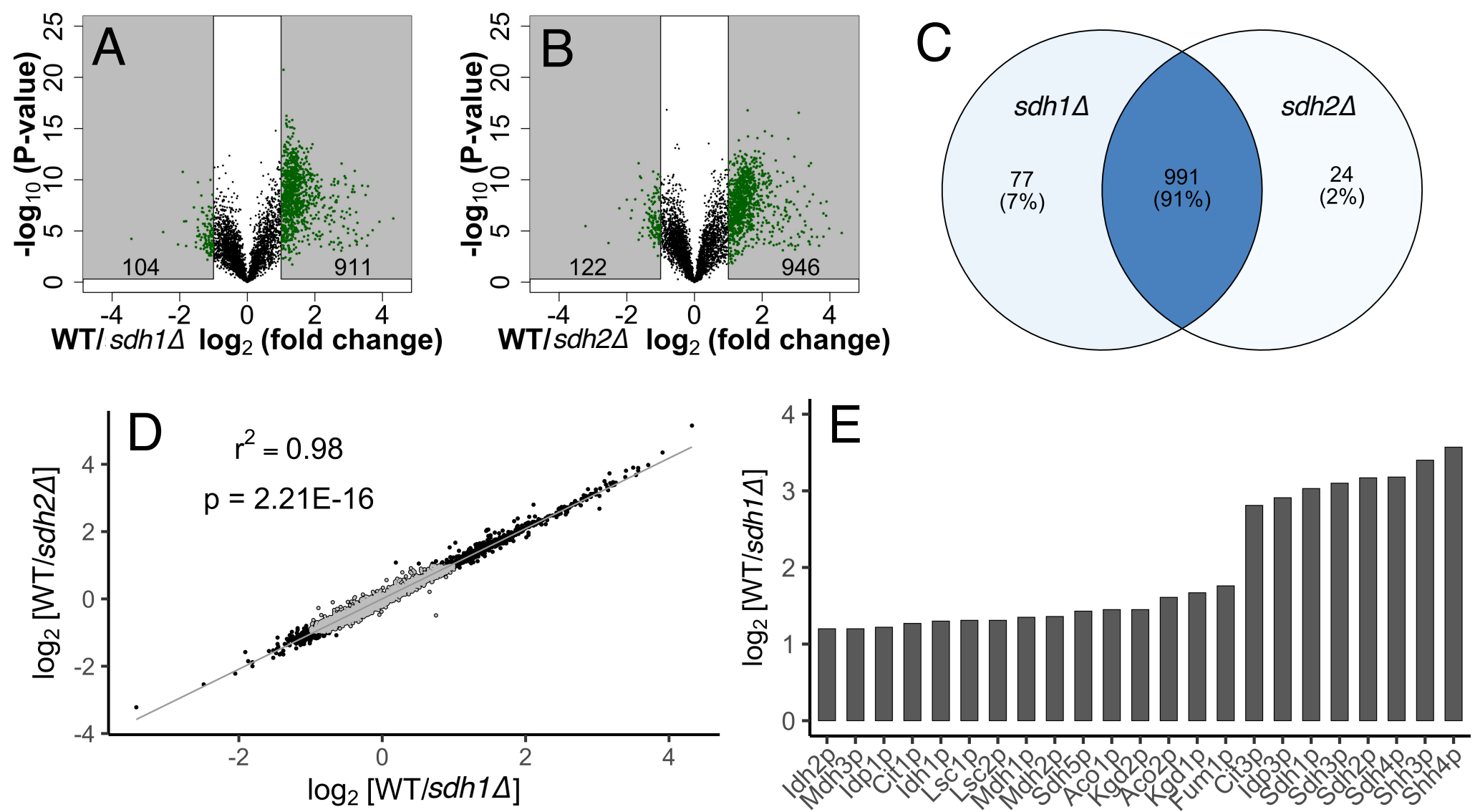

Fig 3 


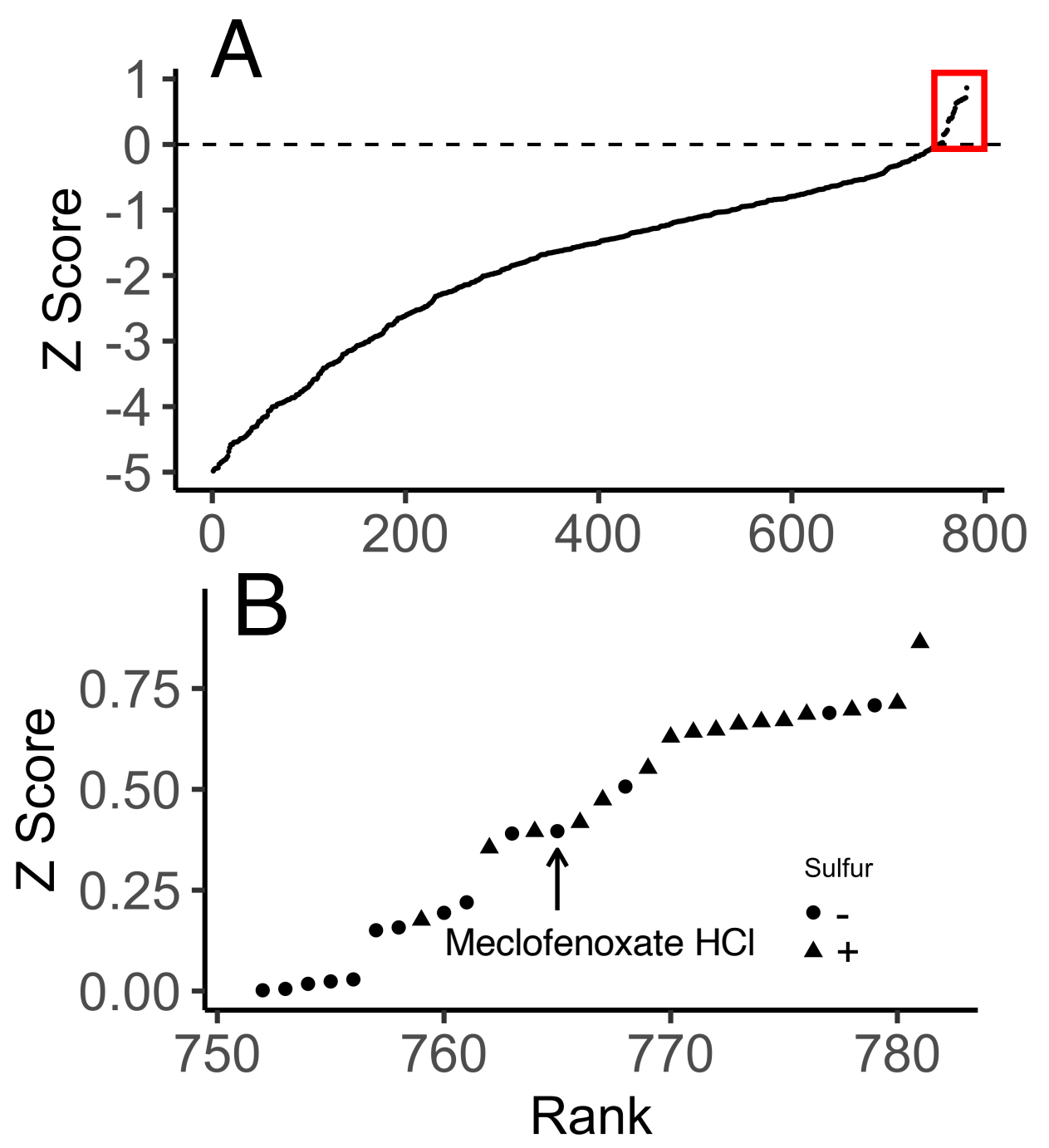

Fig 4 


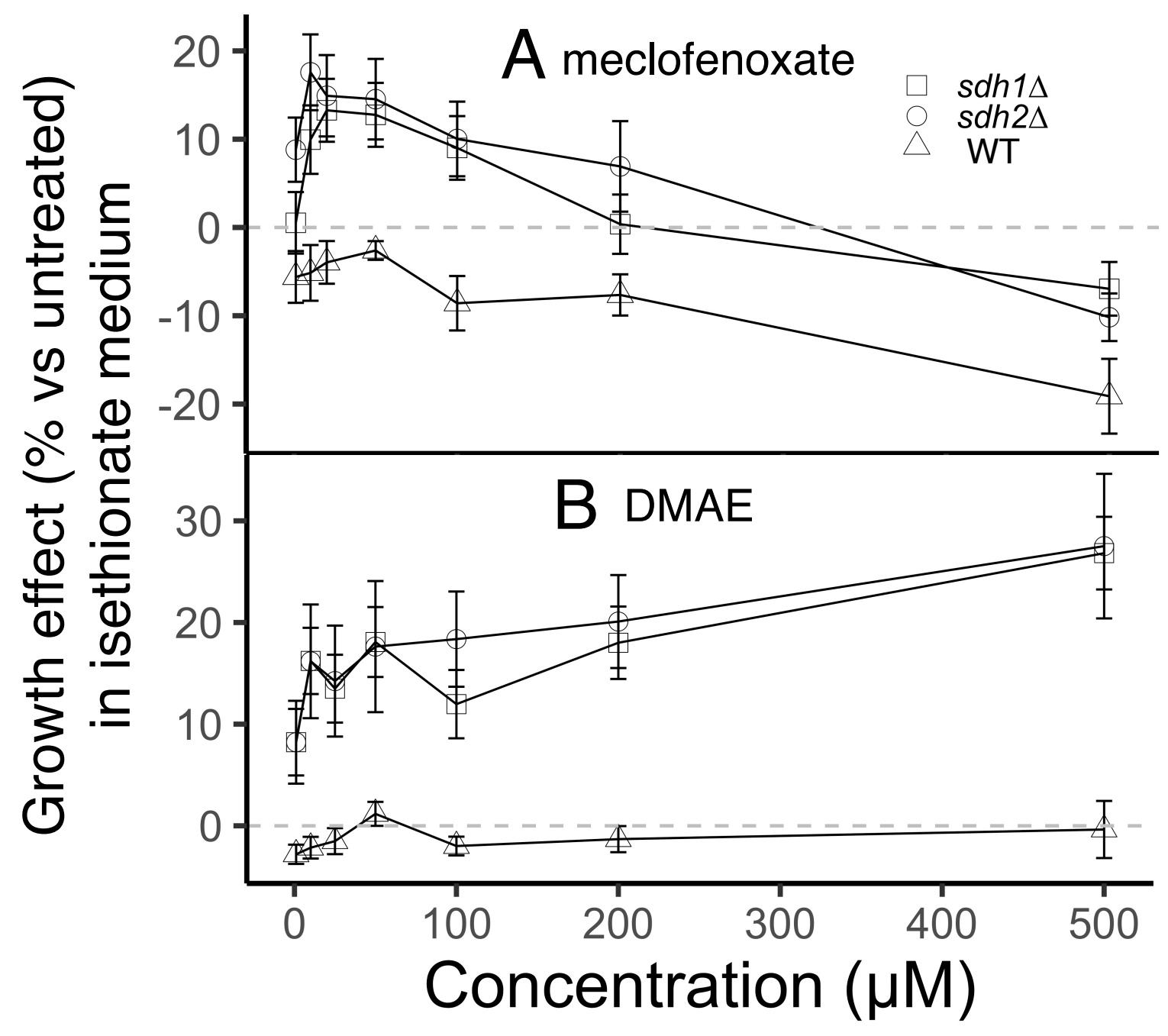

Fig 5 


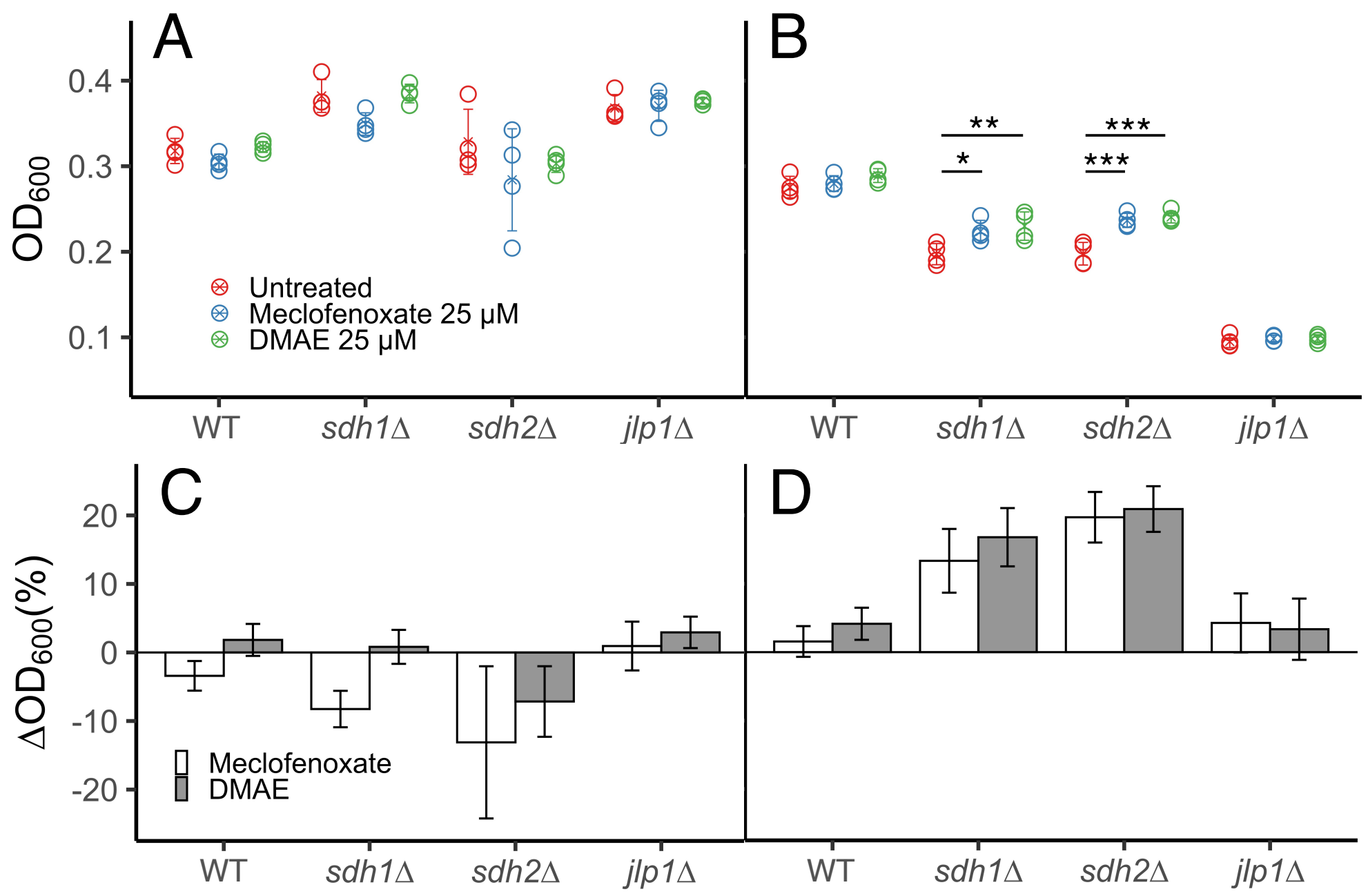

Fig 6 


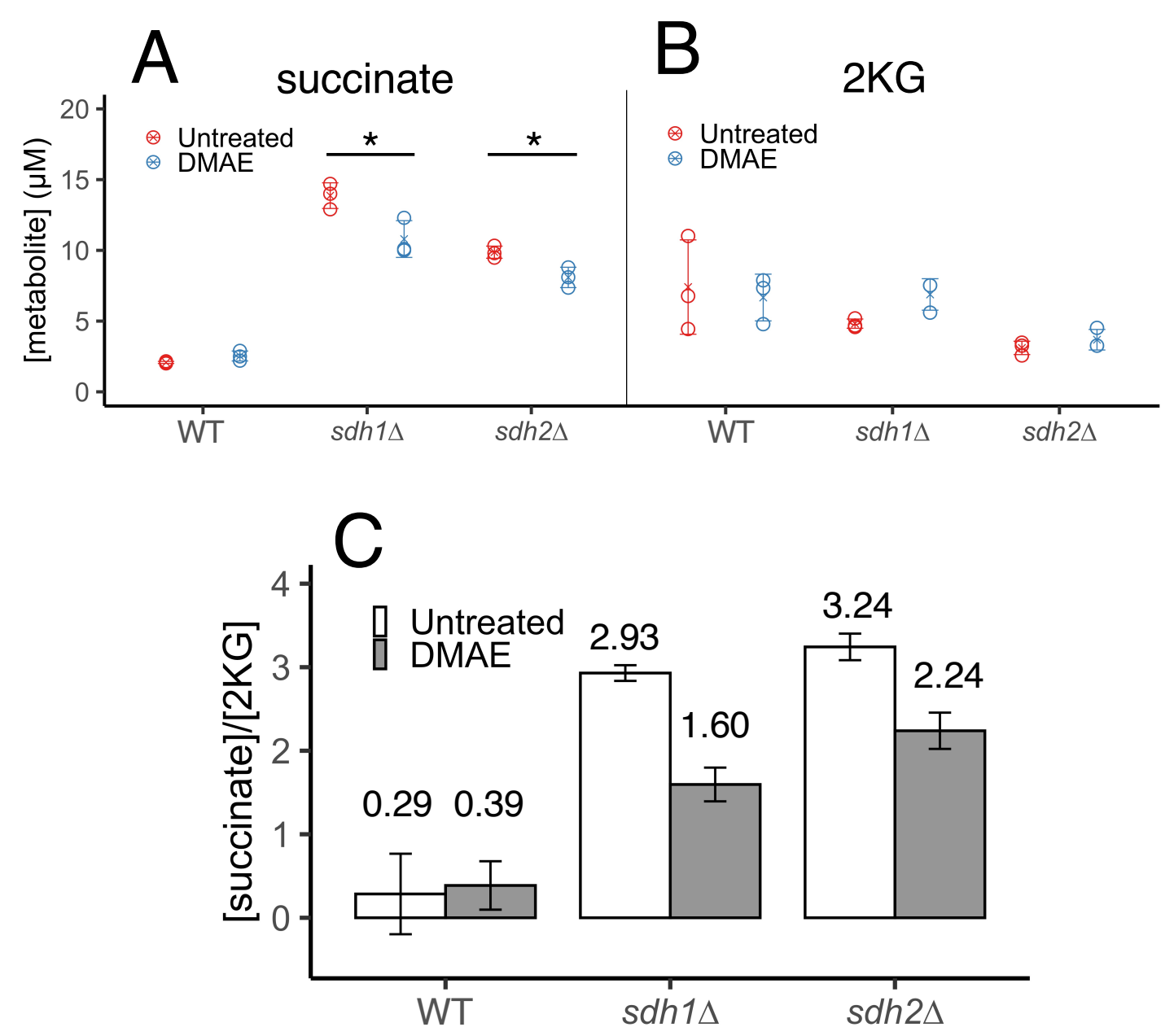

Fig 7 

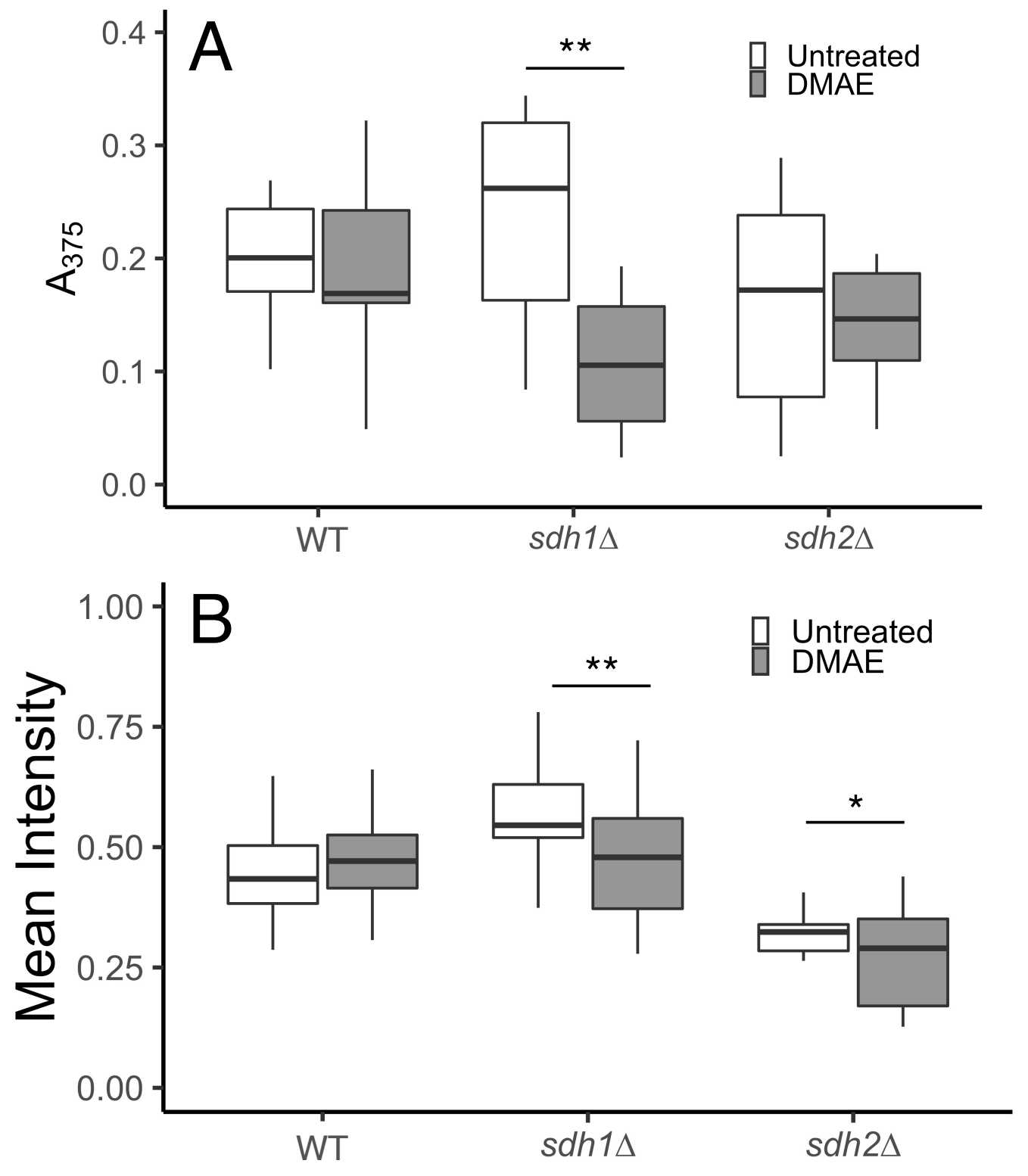

Fig 8 